\title{
Inconstitucionalidad de la agravante establecida en el artículo 47 numeral 20 del código orgánico integral penal
}

\section{Unconstitutionality of the aggravant established in article 47 numeral 20 of the comprehensive organic criminal code}

\author{
DOI: $10.46932 / \mathrm{sfjdv2n2-132}$
}

Received in: March 1st, 2021

Accepted in: May 30th, 2021

\author{
Milton Iván Carrión Barco \\ Abogado de la República. Universidad Técnica de Machala. Machala - Ecuador \\ E-mail: carrionbm@fiscalia.gob.ec
}

Quinche Labanda Darwin Jeovanny

Magister en Ciencias Penales. Docente Universidad Técnica de Machala. Machala - Ecuador

E-mail: dquinche@utmachala.edu.ec

\section{RESUMEN}

En el Ecuador y la Constitución de la República, la Corte Nacional de Justicia es el máximo órgano de administración de justicia ordinaria, será su presidente quien represente a la Función Judicial del país; la función general de la Corte Nacional de Justicia consiste en garantizar la seguridad jurídica y la tutela segura de la persona procesada; con base en este contexto se ha planteado como objetivo de la investigación, determinar la inconstitucionalidad de la agravante establecida en el artículo 47 numeral 20 del Código Orgánico Integral Penal, por vulnerar el principio procesal de "presunción de inocencia", garantizado en el mismo cuerpo legal, en el artículo 5 numeral 4 y principalmente el artículo 76 numeral 2 de la Constitución de la República del Ecuador, para esto se recurrió a la investigación bibliográfica de publicaciones cientificas publicadas en revistas indexadas, al igual que las revisiones narrativas y jurisprudenciales; como resultado de la investigación se pudo evidenciar la inconstitucionalidad del artículo 47 numeral 20 del Código Orgánico Integral Penal, mediante el cual es posible que el juzgador pueda agravar la pena cuando se trata de una persona que ha sido aprehendida en delito flagrante, por lo que se conoce a esta realidad como algo antijurídico, debido a que cuando un individuo es aprehendido eso no expresa que sea culpable, se debe seguir un proceso y mediante la sentencia ejecutoriada resolver la responsabilidad del delito imputado; se vulnera el proceso al emplear la aprehensión previa como agravante, violando derecho a la tutela judicial.

Palabras clave: justicia, seguridad jurídica, delito flagrante, agravante, inconstitucionalidad

\begin{abstract}
In Ecuador and the Constitution of the Republic, the National Court of Justice is the highest organ of administration of ordinary justice, its president will be the one who represents the Judicial Function of the country; The general function of the National Court of Justice consists of guaranteeing legal security and safe guardianship of the processed person; Based on this context, the objective of the investigation has been proposed to determine the unconstitutionality of the aggravating circumstance established in article 47, numeral 20 of the Comprehensive Organic Criminal Code, for violating the procedural principle of "presumption of innocence", guaranteed in the same body legal, in article 5 numeral 4 and mainly article 76 numeral 2 of the Constitution of the Republic of Ecuador, for this we resorted to bibliographic research of scientific publications published in indexed journals, as well as narrative and jurisprudential reviews; As a result of the investigation, the unconstitutionality of article 47 numeral 20 of the Comprehensive
\end{abstract}


Organic Penal Code could be evidenced, by means of which it is possible that the judge may aggravate the penalty when it comes to a person who has been apprehended in flagrante delicto, for which reason This reality is known as something unlawful, because when an individual is apprehended it does not express that he is guilty, a process must be followed and by means of the enforceable sentence resolve the responsibility of the imputed crime; the process is violated by using prior apprehension as an aggravating factor, violating the right to judicial protection.

Keywords: justice, legal certainty, flagrant crime, aggravating, unconstitutionality

\section{INTRODUCCIÓN}

De acuerdo con la Constitución de la República del Ecuador, la Corte Nacional de Justicia es el máximo órgano de administración de justicia ordinaria, su presidente es quien va a representar a la Función Judicial del país. La función general de la Corte Nacional de Justicia consiste en garantizar la seguridad jurídica y la tutela segura de la persona procesada.

La administración de justicia gira alrededor de los siguientes ejes: respeto al derecho al proceso apropiado, a la seguridad jurídica, y a la defensa judicial efectiva. El derecho a sancionar evitando arbitrariedades es posible siempre y cuando se reconozca y se cumpla lo establecido en la Constitución de la República y las leyes, al mismo tiempo se cristaliza el acceso libre y eficaz a la justicia (Ramírez \& Tello, 2017).

Las autoridades encargadas de administrar justicia son los jueces y juezas, estos tienen como obligación aplicar y hacer que se aplique lo que está establecido en la Constitución de la República, los instrumentos internacionales de Derechos Humanos y en la ley. Todos los individuos que forman parte de la sociedad deben tener la convicción de que los actos que comenten pueden tener consecuencias jurídicas, los cuales serán juzgados por jueces y juezas cualificados y objetivos.

Con la finalidad de garantizar la confianza de los ciudadanos al momento de resolver sus controversias, al igual que la plenitud del respeto de las garantías procesales, las autoridades encargadas de impartir justicia deben tener claros los criterios de interpretación y aplicación de las normas, al igual que de la jurisprudencia, de esta manera se evita cometer actos inconstitucionalidades.

La presente investigación se enfocó en la inconstitucionalidad que puede existir al momento de defender al procesado durante el procedimiento que se da en los delitos flagrantes. El objetivo general de la investigación es:

Determinar la inconstitucionalidad de la agravante establecida en el artículo 47 numeral 20 del Código Orgánico Integral Penal, por vulnerar el principio procesal de "presunción de inocencia", garantizado en el mismo cuerpo legal, en el artículo 5 numeral 4 y principalmente el artículo 76 numeral 2 de la Constitución de la República del Ecuador. 
También se plantearon objetivos especificos para la investigación, los cuales se detallan a continuación:

Establecer que existe incongruencia entre la agravante establecida en el artículo 47 numeral 20 y artículo 57 del CÓDIGO ORGÁNICO INTEGRAL PENAL, que hace relación a la reincidencia.

Establecer que la garantía constitucional de "presunción de inocencia", se encuentra restringida por el artículo 47 numeral 20 del Código Orgánico Integral Penal, inaplicando lo dispuesto en el numeral 4 del mismo cuerpo legal, donde se reconoce que ninguna norma jurídica puede restringir el contenido de los derechos ni de las garantías constitucionales.

Establecer que el aumento de penas o agravantes a los delitos alimenta el populismo punitivo y reduce los beneficios o garantías de excarcelación, sin cumplir con los estándares de seguridad ciudadana deseados.

\section{METODOLOGÍA}

La investigación realizada es de tipo no experimental, debido a que no se manipula variables; también es bibliográfica, se recurrió a la revision de información procedente de artículos de revistas, libros y registros bibliográficos y códigos, al igual que revisiones narrativas y jurisprudenciales.

Se recurrió al método analítico sintético para establecer mediante el marco teórico la posición de distintos juristas doctrinarios en relación con la presunción de inocencia y su aplicación en relación a la aprehensión previa en delito flagrante como agravante de la infracción, de esta manera se pudo ponderar y obtener una síntesis y conclusiones que sirvan de beneficio a la investigación.

\section{DESARROLLO}

El Ecuador es un estado constitucional de derechos y justicia, según lo establece la Constitución de la República, esta es la norma suprema y jerárquica dentro de la norma jurídica, este cuerpo legal deberá ser acatado por sobre todas las leyes, debe ser respetado por todos los órganos de administración de justicia y buscar que sus principios y derechos fundamentales se apliquen de manera eficaz, de esta manera será posible cumplir adecuadamente con el proceso para obtener una verdadera justicia constitucional para los ciudadanos y no provocar una inseguridad jurídica (Duran et al., 2018).

El 24 de diciembre del año 2019 se publicaron en el Registro Oficial Suplemento $\mathrm{N}^{\circ}$ 107, las reformas al Código Orgánico Integral Penal (COIP), discutidas y aprobadas previamente por la Asamblea Nacional de la República del Ecuador. Entre las reformas al COIP se encuentra el artículo 47 numeral 20, el cual infringe el principio procesal de "presunción de inocencia", presente en la Constitución de la República del Ecuador, artículo 76 numeral 2. 
De acuerdo con el artículo 47 numeral 20 mencionado anteriormente, el juzgador puede agravar el quantum de la pena al establecer circunstancias agravantes como la detención de la persona en un delito flagrante, atentando así contra la disposición legal del principio de inocencia. La norma establece:

Art. 47.- Circunstancias agravantes de la infracción. - Son circunstancias agravantes de la infracción penal: Registrar la o el autor una o más aprehensiones previas en delito flagrante calificado, cuando se trate del mismo delito o atente contra el mismo bien jurídico protegido (Asamblea Nacional del Ecuador, 2021).

\section{LA PRESUNCIÓN DE INOCENCIA Y EL IN DUBIO PRO REO}

A nivel internacional, la presunción de inocencia es expresada de maneras sustancialmente iguales, se considera inocente a la persona mientras no se halla establecido su culpabilidad, acorde como lo establece la ley y mediante sentencia (Sanabria, 2019).

De acuerdo con la Convención Americana sobre Derechos Humanos, toda persona inculpada de delito tiene derecho a que se presuma su inocencia mientras no se establezca legalmente su culpabilidad. Durante el proceso, toda persona tiene derecho, en plena igualdad, a las siguientes garantías mínimas: derecho de recurrir del fallo ante juez o tribunal superior (Suprema Corte de Justicia de la Nación, 2014).

La presunción de inocencia como derecho puede ser violada por la autoridad jurisdiccional del juzgador del juzgador y por cualquier autoridad pública; de acuerdo a lo establecido por el Art. 6.2 de la Convención Europea, informar a la sociedad en relación con investigaciones criminales en proceso no es prohibido, sin embargo, estas acciones se deben llevar bajo discreción, de esta manera se respeta la presunción de inocencia del procesado.

Como se citó en el art. 8.2 de la Convención Americana de Derechos Humanos, existen ciertas exigencias para que el estado no condene o emita un juicio hacia la población, ya que se estaría dando ejemplo para que se forme la opinión pública, contra lo que sea posible atestiguar bajo el amparo de la ley, al igual que la responsabilidad penal que una unidad jurisdiccional pueda establecer.

De acuerdo con el profesor Orlando Rodríguez, de la Facultad de Estudios Superiores Acatlán, México, parte esencial de la presunción de inocencia es el in dubio pro reo, según el cual, de existir dudas y ausencia de conocimiento al momento de dictar sentencia condenatoria, se deberá resolver a favor del acusado, absolviendo en cumplimiento del principio de la presunción de inocencia (Bustamante \& Palomo, 2018).

Aplicar la presunción de inocencia sigue un escenario de duda razonable en relación a la existencia del hecho o participación del procesado, es decir, si existe alguna certeza de inocencia, el indulto no debe someterse a la aplicación de la presunción de la inocencia, por lo que surgen dudas al respecto en relación 
a si se debe definir o no el campo de acción de la presunción de inocencia y su correlación con el principio del in dubio pro reo.

\section{INCONSTITUCIONALIDAD DE LA AGRAVANTE ESTABLECIDA EN EL ARTÍCULO 47 NUMERAL 20 DEL CÓDIGO ORGÁNICO INTEGRAL PENAL}

El derecho a una tutela judicial efectiva, presunción de inocencia y el derecho a la defensa son vulnerados por el numeral 20 del artículo 47 del COIP, tomando en cuenta que el individuo sentenciado por una infracción penal verá agravada su situación jurídica si se establece que cuenta con una aprehensión previa, debido a que la norma no hace referencia a una sentencia condenatoria previa.

En definitiva, la persona puede haber ratificado su inocencia en el proceso anterior, sin embargo, el antecedente puede resultar suficiente para agravar su situación, tomando en cuenta que se lo estaría sancionando por una aprehensión que no tiene que ver con el proceso que se le sigue en la actualidad, esto haría que se le imponga condenas desmedidas vulnerando el principio de inocencia.

\section{INCONGRUENCIA ENTRE LA AGRAVANTE ESTABLECIDA EN EL ARTÍCULO 47 NUMERAL 20 Y ARTÍCULO 57 DEL COIP}

De acuerdo al artículo 57 del COIP, se considera reincidencia el cometimiento de un nuevo delito por parte de la persona procesada por medio de sentencia ejecutoriada, y solo procederá la reincidencia en caso de tratarse de la misma infracción penal o atentado contra el mismo bien jurídico, en este caso se deberán concordar los mismos elementos de culpa.

Como se explicó anteriormente, la reincidencia instituye la repetición de un acto que fue penado anteriormente, esto implica que se estaría incurriendo en el pasado judicial de la persona, por lo que resulta inconstitucional juzgar nuevamente a una persona por el mismo acto, se estaría infringiendo la constitución si se sanciona al sujeto no sólo por acciones materia de juzgamiento sino además por su forma de vida, se estaría dejando de lado la culpabilidad por el hecho juzgado y dándole relevancia a las penas privativas de la libertad cumplidas anteriormente.

La aplicación del Art. 57 del COIP sería inconstitucional por cuanto el individuo considerado reincidente por cometer un delito deberá ser juzgado sin considerar sus antecedentes, es decir solamente considerando el ilícito cometido en la actualidad y no como la reincidencia de un delito anterior.

El artículo 76, numeral 7 Literal I de la Constitución del Ecuador establece el principio del derecho a la defensa, el cual señala que nadie puede ser juzgado por iguales hechos y materia, es decir que al establecerse en el artículo 47 numeral 20 del COIP, la aprehensión como agravante de la pena a imputar 
y no instituir sentencia condenatoria, se estaría recayendo en un doble juzgamiento, debido a que la causa de la aprehensión podría no ser juzgada al momento de decretar sentencia en otra causa.

\section{RESTRICCIÓN DE LA PRESUNCIÓN DE INOCENCIA POR EL ARTÍCULO 47 NUMERAL 20 DEL COIP}

De acuerdo con el artículo 4 numeral 4 del COIP, toda persona conserva su estatus jurídico de inocencia por lo que debe ser tratada como tal, mientras no se compruebe lo contrario, es decir, en el numeral 20 del artículo 47 del COIP se estaría violando la presunción de inocencia por omisión, esto se puede producir debido la norma contiene el calificativo de aprehensión y no de sentencia condenatoria.

El principio rector del derecho penal es la presunción de inocencia, por lo cual, si no existe una sentencia condenatoria de por medio, el encargado de administrar justicia estaría procediendo de manera arbitraria si asume la culpabilidad del acusado y toma en cuenta medidas que se deberían aplicar solo al tratarse de una persona que haya sido declarada culpable.

\section{ALIMENTACIÓN DEL POPULISMO PUNITIVO Y REDUCCIÓN DE LOS BENEFICIOS O GARANTÍAS DE EXCARCELACIÓN}

Las políticas criminales propuestas en el Ecuador se encaminan al endurecimiento de penas, con la premisa de prevenir el delito, la idea de esto es que supuestamente la delincuencia se verá disminuida, sin embargo, algo que se ignora es que el endurecimiento de penas no es la solución sino un verdadero proceso de rehabilitación y mejoras significativas en la educación.

El término populismo punitivo hace referencia al uso del derecho penal por parte de los políticos para la obtención de réditos, es decir, se busca generar un sentimiento colectivo para hacer ver a la pena como un método para dar solución a los problemas y disminuir los delitos (Mesa, 2018).

El pretexto de luchar contra la inseguridad en los diferentes ámbitos, el populismo punitivo ha venido aprovechando la escasa confianza de los ciudadanos en la justicia, por lo que se ha ido expandiendo a nivel mundial, como consecuencia de esto se han reducido los beneficios o garantías de excarcelación, de esta manera se han presentado incongruencias que restringen la preseuncion de inocencia, uno de estos en el Ecuador, el artículo 47 numeral 20 del COIP (Focás et al., 2020).

El derecho a la impugnación procesal es reconocido como un derecho y un principio según el artículo 653, por lo que la persona procesada debe tener la posibilidad de recurrir a este derecho. Si no existe sentencia condenatoria previa, sino solo aprehensiones para calificar de agravante de la infracción, se estaría menoscabando el principio al adecuado proceso. 


\section{CONCLUSIONES}

Una vez fundamentada de manera teórica y doctrinaria en relación con la aprehensión previa en delitos flagrantes, es posible concluir que, de acuerdo al numeral 20 del Art. 47 del Código Orgánico Integral Penal, es posible que el juzgador pueda agravar la pena cuando se trata de una persona que ha sido aprehendida en delito flagrante, por lo que se conoce a esta realidad como algo antijurídico, debido a que cuando un individuo es aprehendido eso no expresa que sea culpable, se debe seguir un proceso y mediante la sentencia ejecutoriada resolver la responsabilidad del delito imputado.

El debido proceso es vulnerado al momento de emplear la aprehensión previa como agravante, el numeral 20 del Art. 47 del Código Orgánico Integral Penal viola el derecho a la tutela judicial efectiva y el derecho a la defensa, al momento que se considera la aprehensión en delitos flagrantes como agravante, así haya existido una interrupción se le considera culpable sin que pueda defenderse y sin poder impugnar la realidad en la que lo ha puesto esta regulación normativa, de esta manera se estaría incumpliendo con dos principios básicos del debido proceso.

En lo que respecta a la preparación de los componentes del documento de análisis crítico relacionado con la aprehensión previa en delito flagrante como agravante de la infracción y la presunción de inocencia, es posible concluir que no se rompe el estado de inocencia de una persona por haber sido aprehendida en delito flagrante como agravante de la infracción y la presunción de inocencia, la única manera de que esto suceda es mediante la sentencia ejecutoriada en la cual se establezca el gravamen en el cometimiento del delito, sin embargo, al ser aplicada la aprehensión en delito flagrante como agravante descontextualiza y destroza completamente el principio de inocencia.

La problemática planteada debe solventarse mediante el planteamiento de una demanda de inconstitucionalidad a la Corte Constitucional, y sea esta la que se pronuncie en relación con el numeral 20 del artículo 47 del Código Orgánico Integral Penal, esto permitirá que cuando el juzgador establezca la sentencia condenatoria no agrave quantum de la pena, al instituir una circunstancia agravante como es la aprehensión de la persona en un delito flagrante, atentando así a la presunción de inocencia.

La intención de este trabajo de investigación es que las reformas legales recomendadas sean presentadas como proyecto de ley reformatoria a la Asamblea Nacional, que se plantee de la siguiente manera el numeral 20 del Art. 47 de la Ley Reformatoria al Código Orgánico Integral Penal: 20. Consignar la o el autor una o varias sentencias condenatorias, en aquellos casos en los que se trate del mismo delito o en su defecto, atente contra el mismo bien jurídico protegido. 


\section{BIBLIOGRAFÍA}

Asamblea Nacional del Ecuador. (2021). Código Orgánico Integral Penal. Registro Oficial Suplemento $180,248,1-144$.

Bustamante, M., \& Palomo, D. (2018). La presunción de inocencia como regla de juicio y el estándar de prueba de la duda razonable en el proceso penal. Una lectura desde Colombia y Chile. Ius et Praxis, 24(3), 651-692. https://doi.org/10.4067/s0718-00122018000300651

Duran, A., Sánchez, M., \& Vilela, E. (2018). Inconstitucionalidad en la defensa del procesado dentro de un procedimiento directo en los delitos flagrantes. Universidad y Sociedad, 10(2), 318-322. http://scielo.sld.cu/pdf/rus/v10n2/2218-3620-rus-10-02-323.pdf

Focás, B., Marroquín, A., \& Simeón, J. (2020). Revisitando la agenda de la seguridad en América Latina. Revista CS, 1(31), 13-16. https://doi.org/10.18046/recs.i31.3997

Mesa, L. (2018). Derecho a la igualdad para victimarios de delitos sexuales en las tres fases de criminalización. Revista Investigare, 4(1), 1-34. https://cutt.ly/3nddGmT

Ramírez, C., \& Tello, M. (2017). Criterios sobre inteligencia y aplicación de la ley Materias Penales (C. N. de Justicia (ed.); Primera ed).

Sanabria, A. (2019). Presunción de inocencia en materia de procedimiento administrativo sancionador. Matices y modulaciones. Derecho Global. Estudios Sobre Derecho y Justicia, 4(10), 51-76. https://doi.org/https://doi.org/10.32870/dgedj.v0i10.195

Suprema Corte de Justicia de la Nación. (2014). Convención Americana sobre Derechos Humanos comentada. In Derechos Humanos en la constitucion. https://cutt.ly/Gndkk20 